\title{
Coronary artery perforation during diagnostic coronary angiography resulting in acute pericarditis
}

\author{
Serkan Duyuler', Pınar Türker Bayır², Ahmet Korkmaz', Ümit Güray², Halil Lütfi Kısacık ${ }^{4}$ \\ ${ }^{1}$ Cardiology Clinic, Hakkari State Hospital, Hakkari, Turkey \\ ${ }^{2}$ Cardiology Clinic, Ankara Numune Training and Research Hospital, Ankara, Turkey \\ ${ }^{3}$ Cardiology Clinic, Çankırı State Hospital, Çankırı, Turkey \\ ${ }^{4}$ Cardiology Clinic, Türkiye Yüksek intisas Training and Research Hospital, Ankara, Turkey
}

Postep Kardiol Inter 2013; 9, 3 (33): 298-300

DOI: $10.5114 /$ pwki.2013.37515

\begin{abstract}
We report a case of coronary artery perforation during diagnostic coronary angiography. No cardiac biomarker elevation was observed. However, the patient suffered acute pericarditis which was treated conservatively.
\end{abstract}

Key words: coronary artery, perforation, pericarditis.

A 44-year-old female patient was admitted to our clinic with exertional angina. She has a family history of premature coronary artery disease as a conventional cardiac risk factor. Electrocardiogram revealed normal sinus rhythm. Since stress electrocardiogram was equivocal for ischemia, coronary angiography was scheduled. During coronary angiography, the diagnostic coronary catheter spontaneously engaged deeply into the small caliper intermediate coronary artery after the first contrast injection to the left main coronary artery. Following contrast injection resulted in rupture of the intermediate artery secondary to injection pressure (Figures $1 \mathrm{~A}-\mathrm{D}$ ). Extravasation of the contrast material was limited to the myocardium and did not pass into the pericardial space. Control echocardiography showed no wall motion abnormality or pericardial effusion. No cardiac biomarker elevation was observed during follow-up however the patient described chest pain compatible with acute peri- carditis secondary to coronary accident. This diagnosis was also supported by electrocardiography (Figures 2 and 3). Since the patient was stable, no further intervention was scheduled and she was discharged without any sequel after a 3-day hospitalization.

Coronary artery rupture is an exceedingly rare complication during diagnostic coronary angiography and reported cases are mostly secondary to percutaneous coronary interventions. Presence of a small-calibre intermediate coronary artery which is coaxial to the left main coronary artery may deserve additional care to avoid deep engagement which may result in potentially catastrophic coronary artery rupture. Depending on the location and severity of the rupture, covered stent implantation, coil embolisation and surgery may be a treatment option. As we observed in our patient, for self-limiting ruptures in haemodynamically stable cases, a conservative strategy may be promising. 

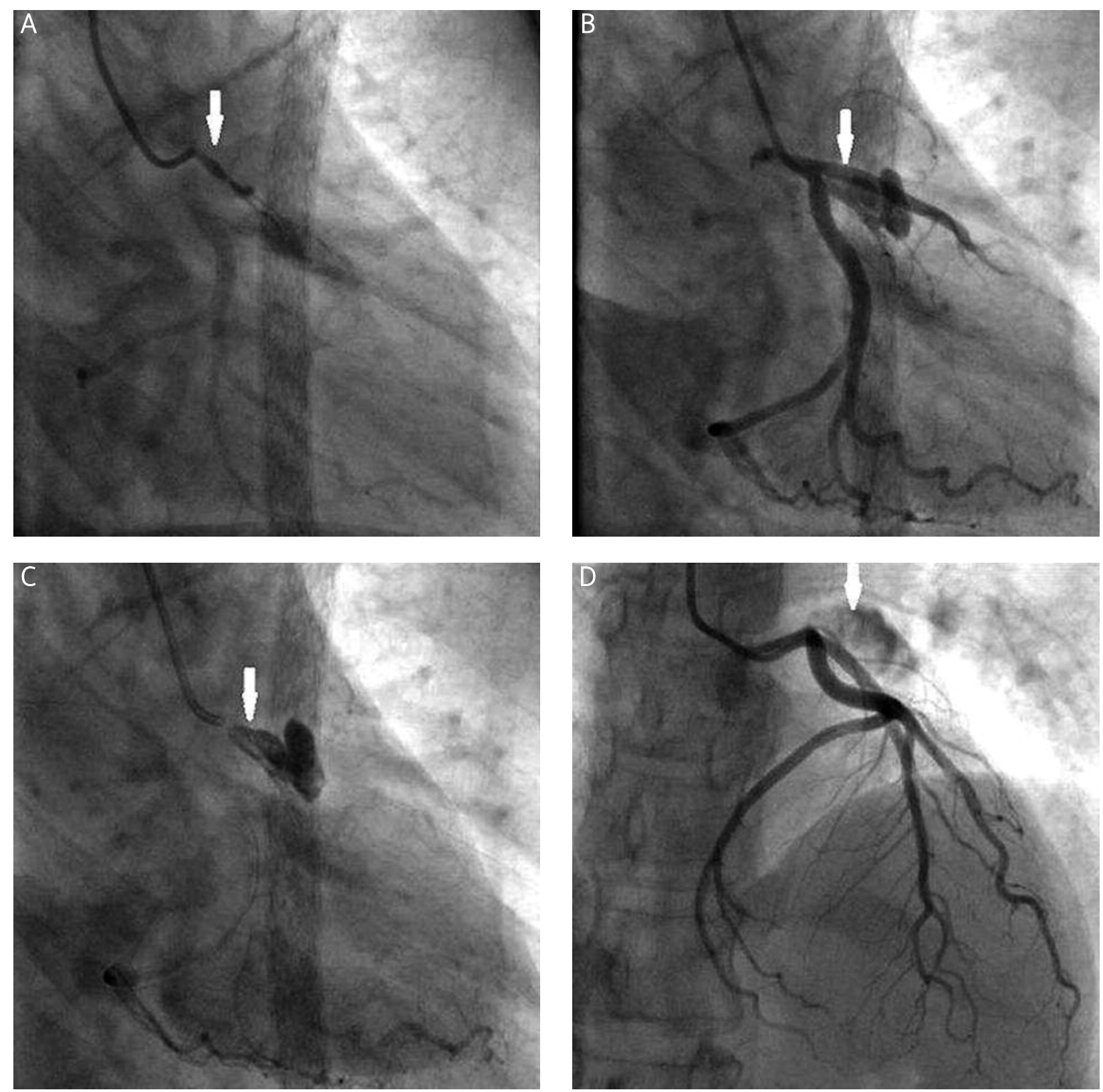

Fig. 1. A-D. Deep engagement of coronary catheter into intermediate coronary artery ostium. Coronary artery perforation and contrast material extravasation after contrast injection (arrow) 


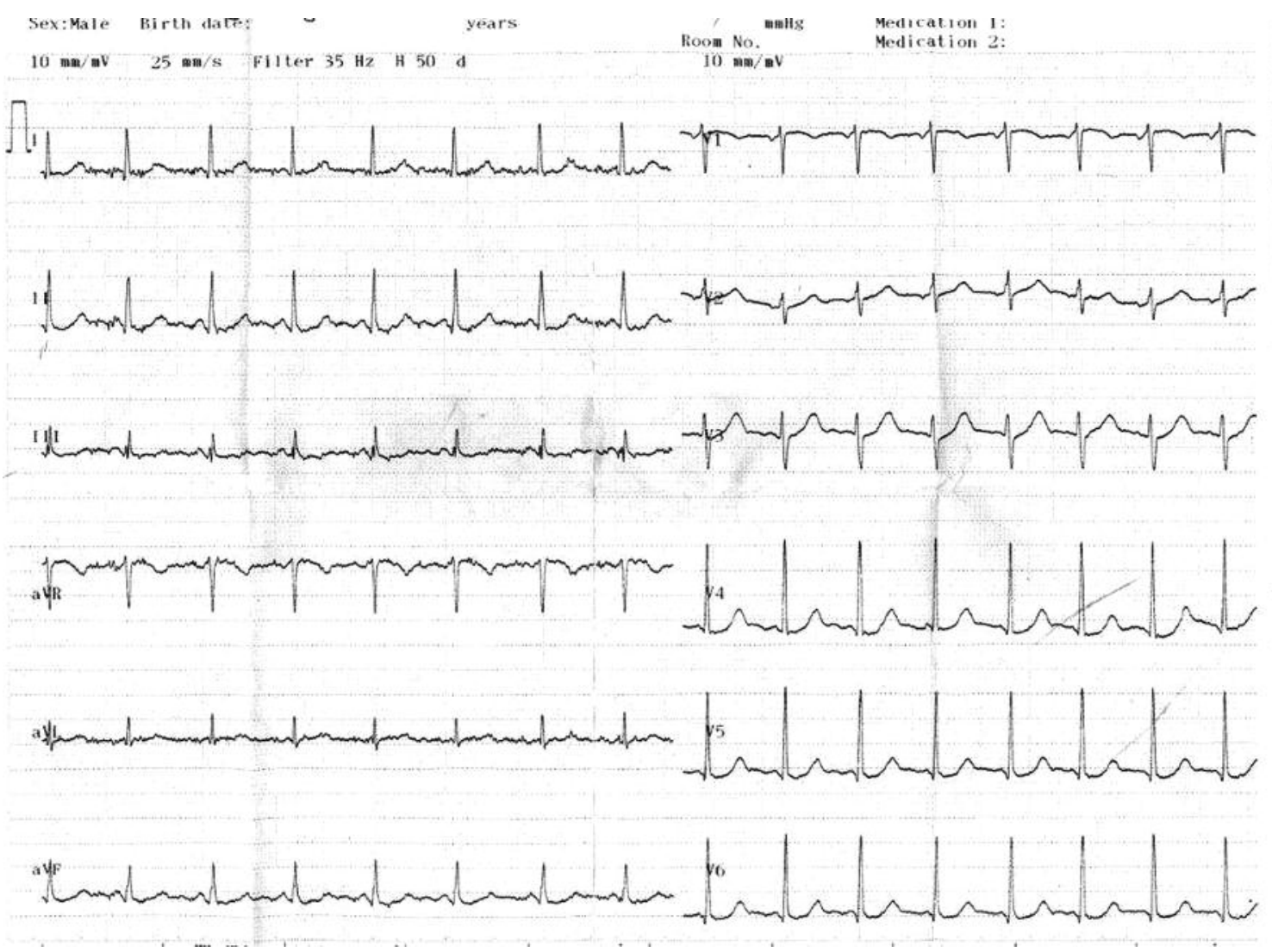

Fig. 2. Pre-procedure electrocardiogram

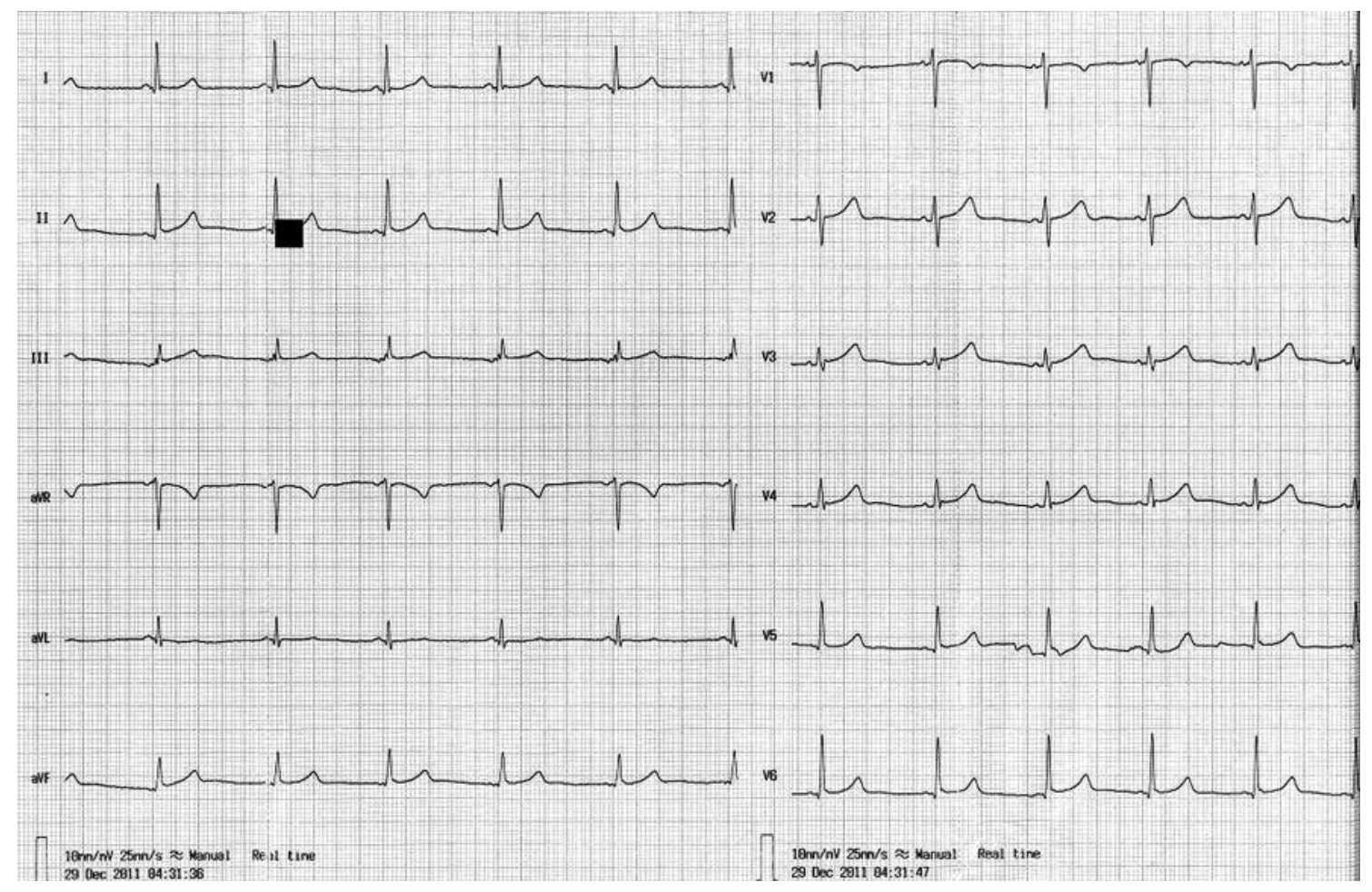

Fig. 3. Electrocardiogram showing saddle-shaped slight ST elevation compatible with acute pericarditis when compared with pre procedure electrocardiogram 